\title{
Bilateral Foot-Drop Secondary to Axonal Neuropathy in a Tuberculosis Patient With Co- Infection of COVID-19: A Case Report
}

Mohammad H. AlKhateeb ${ }^{1}$, Afia Aziz ${ }^{1}$, Mugahid Eltahir ${ }^{1}$, Abdulnasser Elzouki ${ }^{1}$

1. Internal Medicine, Hamad Medical Corporation, Doha, QAT

Corresponding author: Mohammad H. AlKhateeb, mhsk.aw@gmail.com

\begin{abstract}
Tuberculosis (TB) is a global pandemic and is one of the top 10 causes of death worldwide as well as the leading cause of death from a single infectious agent. It can cause a wide array of complications including peripheral neuropathy. In addition to TB pandemic the recent pandemic of coronavirus disease 2019 (COVID-19) has led to an increased interest in the co-infection of TB patients and COVID-19 and whether TB increases risk for COVID-19 and its role in causing severity of disease and vice-versa. This case report discusses about a young cachectic man who was found to have bilateral foot-drop under the setting of $\mathrm{TB}$ with co-infection of COVID-19 later confirmed to be axonal neuropathy on nerve conduction study. The report highlights the importance of differential diagnosis of TB in COVID-19 patients as well as the consideration of TB in a patient with peripheral neuropathy after nutritional causes have been ruled out.
\end{abstract}

Review began $11 / 03 / 2020$ Review ended 11/16/2020 Published 11/28/2020

\section{() Copyright 2020}

AlKhateeb et al. This is an open access article distributed under the terms of the Creative Commons Attribution License CC-BY 4.0., which permits unrestricted use, distribution, and reproduction in any medium, provided the original author and source are credited.
Categories: Internal Medicine, Neurology, Infectious Disease

Keywords: covid-19, novel coronavirus, sars-cov-2 infection, tuberculosis, foot drop, peripheral neuropathy

\section{Introduction}

Tuberculosis (TB) has been a slow pandemic causing major infection-related morbidity and mortality [1]. It has long been known to cause various extra-pulmonary manifestations and can affect any part of the body, one such rarer manifestation that has been associated with it is peripheral neuropathy. How it affects the peripheral nerves has not been studied in great detail; various mechanisms have been linked to this including direct invasion, immune-mediated phenomenon, vasa vasorum inflammation, and effect of antiTB medications, but due to the rarity of this condition limited work has been done on this topic [2-3].

In addition, with the recent pandemic of COVID-19, several studies have come forth regarding the coinfection of TB with COVID-19 with the first set of studies suggesting the synergistic potential of COVID-19 with TB worsening prognosis of TB patients [4-5].

We present a case of a 28 -year-old male diagnosed with miliary TB after developing peripheral neuropathy in the setting of COVID-19.

\section{Case Presentation}

A 28-year-old South Asian male with no relevant past medical history presented with six months history of dry cough and fever. His cough was worse at night, associated with night sweats and $16 \mathrm{~kg}$ unintentional weight loss. It had worsened dramatically with shortness of breath on mild exertion and fever with chills 15 days prior to the patient seeking medical attention. He also noticed difficulty in taking steps around one month ago that progressively worsened to involve weakness in lower limbs around the same time his cough worsened.

On examination, he was found to have generalized muscle wasting and was cachectic, he had bilateral footdrop (Figure 1) as he was walking with a high steppage gait. He also had clubbing with left axillary and supraclavicular lymphadenopathy. The chest exam revealed reduced air entry on the left side with crepitations in the right lung base. Neurological exam initially was significant for loss of dorsiflexion and weak plantar flexion bilaterally with preserved ankle reflexes. Throughout his hospital stay, his neuropathy progressed with further loss of plantar flexion and ankle reflex with additional loss of pain sensation in his feet. 


\section{Cureus}

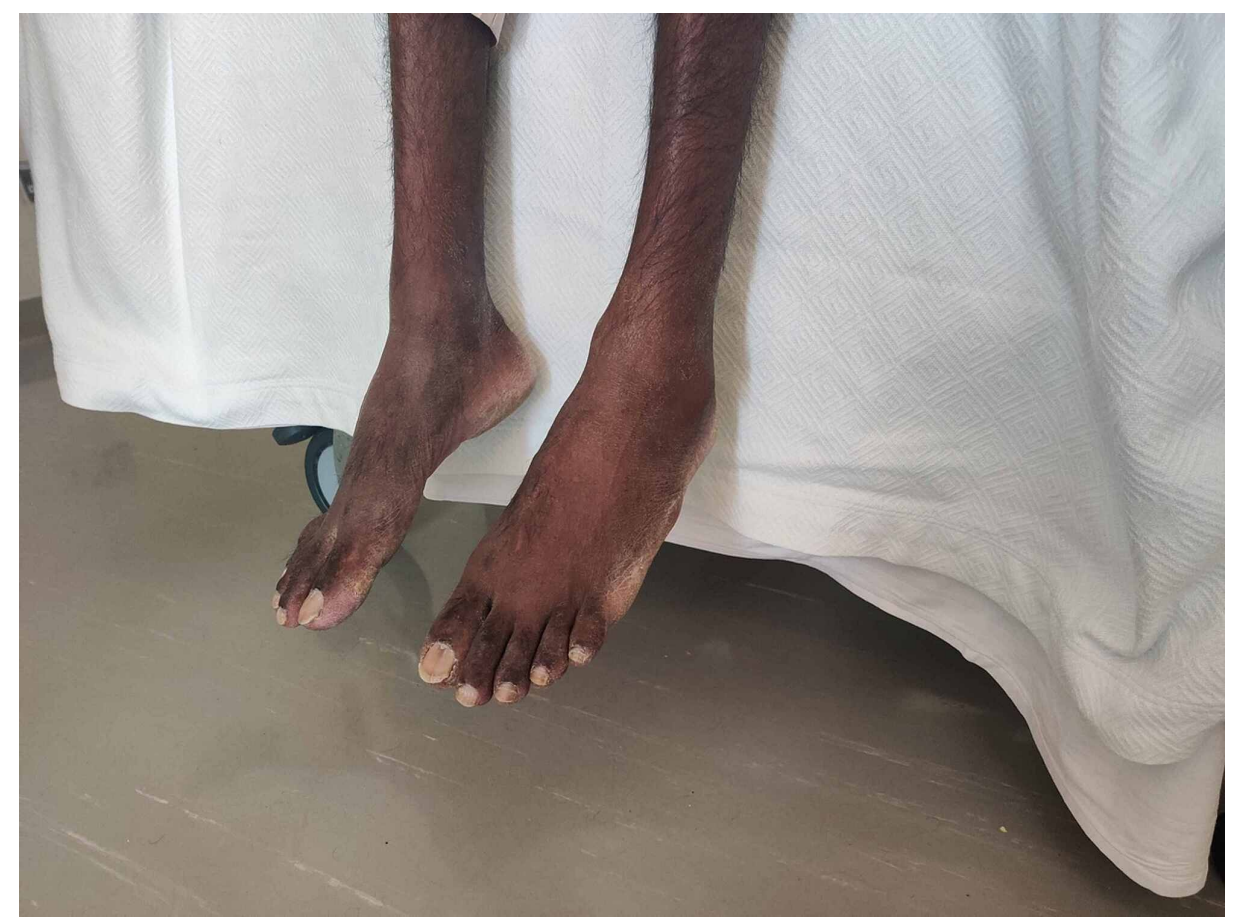

FIGURE 1: Bilateral foot-drop.

The patient was admitted to an isolation unit; first set of COVID testing was positive detected by reverse transcription-polymerase chain reaction (RT-PCR), his chest X-ray showed miliary shadowing (Figure 2). Additionally, he had hypochromic microcytic anemia and lymphocytopenia (Table 1). The patient was initiated on COVID protocol. Further evaluation showed vitamin B12 deficiency with iron stores depletion, elevated serum ferritin, and D-dimer level. HIV was nonreactive. Assessment for TB started with QuantiFERON and sputum for TB (i.e., acid fast bacilli and TB PCR), the patient was treated empirically initially with anti-TB therapy due to high clinical suspicion and chest X-ray findings despite the first set of sputum testing negative for acid fast bacilli. Mycobacterium tuberculosis was detected by PCR after repeated sets of sputum samples as bronchoscopy was delayed due to COVID-19 pandemic concerns. High resolution CT of the chest showed typical features for miliary TB (Figure 3). 


\section{Cureus}

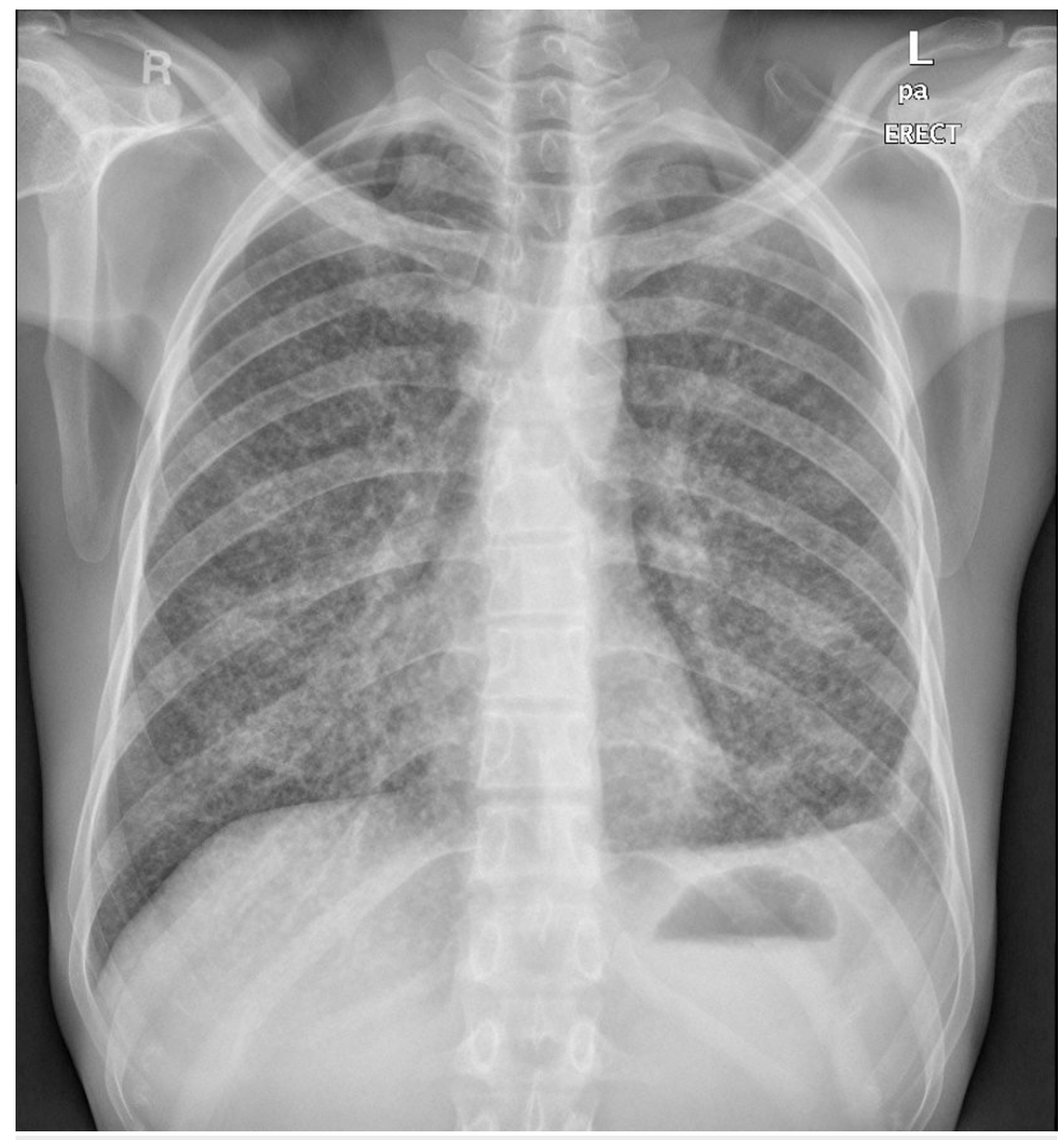

FIGURE 2: Chest X-ray showing bilateral multiple small nodules scattered in the lung fields giving the military shadow with blunting left costophrenic angle. 


\section{Cureus}

\begin{tabular}{|c|c|c|c|c|}
\hline Laboratory tests & Day 1 & Day 2 & Day 15 & Normal range \\
\hline WBC count & 8.5 & 8.2 & 11.4 & $4-10 \times 10^{9} / \mathrm{L}$ \\
\hline Lymphocyte & 0.9 & 0.4 & 1 & $1-3 \times 10^{9} / L$ \\
\hline Hemoglobin & 10.1 & 9.9 & 9.6 & $13-17 \mathrm{gm} / \mathrm{dL}$ \\
\hline Platelets & 398 & 351 & 425 & $150-400 \times 10^{3} / \mu \mathrm{L}$ \\
\hline CRP & 27 & 34.5 & 50 & 0-5 mg/L \\
\hline Lactic acid & 2.5 & - & - & $0.5-2.2 \mathrm{mmol} / \mathrm{L}$ \\
\hline Urea & 3.8 & 2.8 & 4.5 & $2.8-8.1 \mathrm{mmol} / \mathrm{L}$ \\
\hline Creatinine & 50 & 39 & 34 & 62-106 umol/L \\
\hline Sodium & 128 & 135 & 131 & $136-145 \mathrm{mmol} / \mathrm{L}$ \\
\hline Potassium & 4.5 & 3.5 & 3.4 & $3.5-5.1 \mathrm{mmol} / \mathrm{L}$ \\
\hline AST & 44 & 46 & 80 & 0-41 U/L \\
\hline ALT & 61 & 37 & 84 & $0-40 \mathrm{U} / \mathrm{L}$ \\
\hline ALP & 49 & 52 & 134 & 13-53 U/L \\
\hline Billirubin & 15 & 9 & 15 & $0-21$ umol/L \\
\hline LDH & 443 & - & - & $135-225$ U/L \\
\hline INR & 1.2 & - & - & 1 \\
\hline D-dimer & - & 2.62 & - & $0-0.49 \mathrm{mg} / \mathrm{L}$ \\
\hline Ferritin & 1668 & 1651 & 3624 & $30-490$ ug/L \\
\hline Iron & - & 2 & - & 6-35 umol/L \\
\hline TIBC & - & 23 & - & $45-80$ umol/L \\
\hline Transferrin & - & 0.9 & - & $2-3.6 \mathrm{~g} / \mathrm{L}$ \\
\hline Creatine kinase & - & 78 & - & 39-308 U/L \\
\hline Vitamin B12 & - & 73.8 & $>1476$ & $145-596 \mathrm{pmol} / \mathrm{L}$ \\
\hline
\end{tabular}

TABLE 1: Laboratory findings during patient's hospital stay.

WBC, white blood cell; CRP, C-reactive protein; AST, aspartate transaminase; ALT, alanine transaminase; ALP, alkaline phosphatase; LDH, lactate dehydrogenase; INR, international normalized ratio; TIBC, total iron-binding capacity

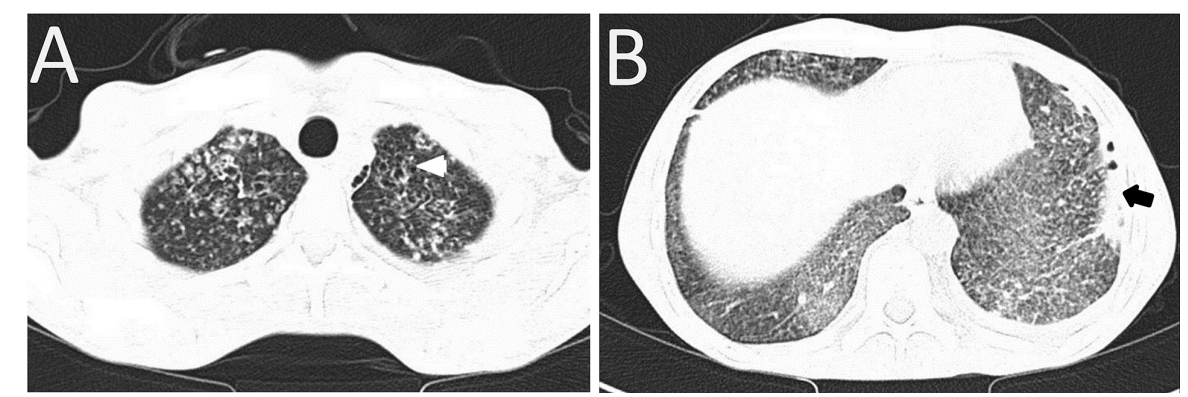

FIGURE 3: High resolution CT-scan showing diffuse innumerable miliary nodules. A. Cystic bronchiectatic changes in upper lobes (arrowhead). B. Left side mild pleural effusion with multiple air fluid level (arrow). 
Peripheral neuropathy initially was attributed to vitamin B12 deficiency, but vitamin B12 replacement showed no improvement instead there was progression of his neuropathy. MRI spine did not show intraspinal, spinal cord, or thecal abnormalities. Nerve conduction study/electromyography (NCS/EMG) done at the time showed severe active sensorimotor axonal distal polyneuropathy with the involvement of bilateral posterior tibial and peroneal motor nerves, severe involvement of bilateral superficial peroneal sensory nerves, and mild involvement of right median and ulnar palmer sensory nerves and bilateral sural sensory nerves (Table 2).

\begin{tabular}{|c|c|c|c|c|c|c|c|c|c|c|c|c|c|}
\hline Muscle & Side & $\begin{array}{l}\text { INS } \\
\text { ACT }\end{array}$ & FIB & PSW & FAS & $\begin{array}{l}\text { MYO } \\
\text { Disc }\end{array}$ & $\begin{array}{l}\text { Normal } \\
\text { MUP }\end{array}$ & POLY & $\begin{array}{l}\text { Low } \\
\text { AMP }\end{array}$ & $\begin{array}{l}\text { High } \\
\text { AMP }\end{array}$ & DUR & RECR & Int Patt \\
\hline Deltoid & Right & Normal & 0 & 0 & 0 & 0 & +3 & $\mathrm{~N}$ & 0 & +1 & Normal & Full & Full \\
\hline First dorsal interosseous & Right & Normal & 0 & +1 & 0 & 0 & +1 & $\mathrm{~N}$ & 0 & +1 & Long & Full & Full \\
\hline Vastus lateralis & Right & Normal & +1 & +2 & 0 & 0 & $\begin{array}{lll}+1 & & \\
\end{array}$ & $\begin{array}{lll}+1 & & \\
\end{array}$ & 0 & +1 & Long & Reduce & Reduce \\
\hline Tibialis anterior & Left & Normal & +2 & +4 & 0 & 0 & $\begin{array}{lll}+1 & & \end{array}$ & $\begin{array}{lll}+1 & & \\
\end{array}$ & 0 & 0 & Normal & Reduce & Reduce \\
\hline Tibialis anterior & Right & Normal & +2 & +4 & 0 & 0 & +1 & +1 & 0 & +2 & Long & Reduce & Reduce \\
\hline $\begin{array}{l}\text { Gastrocnemius. Medial } \\
\text { head }\end{array}$ & Right & Normal & +2 & +3 & 0 & 0 & +1 & ++ & 0 & +2 & Long & Reduce & Reduce \\
\hline $\begin{array}{l}\text { Gastrocnemius. Lateral } \\
\text { head }\end{array}$ & Right & Normal & +2 & +3 & 0 & 0 & +1 & + & 0 & +2 & Long & Reduce & Reduce \\
\hline $\begin{array}{l}\text { Gastrocnemius. Medial } \\
\text { head }\end{array}$ & Left & Normal & +2 & +3 & 0 & 0 & +1 & +1 & 0 & 0 & Long & Reduce & Reduce \\
\hline
\end{tabular}

\section{TABLE 2: EMG findings.}

Needle exam of selected muscles showed spontaneous activity with neurogenic changes more in lower than upper extremities and more distally than proximally.

EMG, electromyography; INS ACT, insertional activity; FIB, fibrillations; PSW, positive sharp wave; FASC, fasciculations; MUP, motor unit potential; POLY, polyphasic units; AMP, amplitude; DUR, duration; RECR, recruitment; Int Patt, interferens pattern; N, normal.

The patient was discharged after getting one month of anti-TB treatment and kept on close follow-up. At six weeks he was contacted over the phone (using telehealth consultation) and as per him his gait and sensations had improved and he could now move his foot upwards. Unfortunately, he was lost to follow-up at eight weeks as he had left the country for good.

\section{Discussion}

Since COVID-19 being declared as a global pandemic [6], co-infection with another pandemic as TB [1] was inevitable. Co-infection case reports have been on the rise [7-11], reaching to a cohort of 69 cases in the literature [5], describing respiratory symptoms almost exclusively without neurological involvement aside from one case that reported TB meningitis [12]. Our patient is an interesting case to report as he had a very rare form of neurological manifestation associated with his miliary TB that is axonal sensorimotor polyneuropathy causing bilateral foot-drop in the background of COVID-19 infection (whether COVID-19 was a confounding factor or synergistic one is unclear due to limited knowledge of this new disease) and malnutrition.

Polyneuropathy is a diffuse peripheral nerve disorder that is not confined to the distribution of a single nerve or a single limb and is relatively symmetrical bilaterally and can be secondary to myelin dysfunction, vasa nervosum compromise, or axonopathy. Causes of axonal polyneuropathy are broad and include a wide variety of conditions including but not limited to diabetes mellitus; uremia; alcohol; nutritional deficiencies including vitamin B12, copper, thiamine, folate, etc; toxins including chemotherapeutic agents, linezolid, amiodarone, isoniazid, etc.; infectious causes including leprosy, lyme disease, and HIV [13].

Even though neurological manifestations of TB have been well documented throughout history in the form of central nervous system involvement such as tuberculous meningitis, tuberculomas and brain abscess, rare manifestations of TB that have been reported are peripheral nervous system involvement in the form of compression by vertebral collapse (Pott's disease) [14], and nerve compression by granulomatous tissue [15]. Still rarer forms include axonal sensorimotor polyneuropathy with only a handful of cases reported in 
literature attributing to variable mechanism: vasculitis, granulomas, and delayed hypersensitivity response [16-18]. Unfortunately, no such details could be isolated from this patient as a peripheral nerve biopsy was not done at the time due to COVID related concerns.

Nutritional causes were taken into consideration with his systemic disease and malnourished picture. But the patient lacked the typical features for vitamin B12 and thiamine deficiency as he had sparing of proprioception without ataxia or ophthalmoplegia [13]. Moreover, vitamin B12 deficiency usually presents as large fiber, sensory myeloneuropathy [19], unlike the nerve conduction study findings of the patient. In addition to his atypical clinical picture, he showed no improvement on prolonged course of vitamin B12 which was initially given in parenteral form then shifted to oral.

Isolated peripheral neuropathy is regularly described in TB patients after receiving anti-TB therapy, which is often responsive to pyridoxine and by discontinuing the offending agent (usually isoniazid) [13]; unlike our case who suffered from neuropathy prior to initiation of anti-TB therapy.

HIV and hepatitis infections have been linked with axonal neuropathy [6] but they were tested negative in our patient. COVID-19 involvement of peripheral nervous system has been mostly linked with GuillainBarre syndrome in which initial data report symptoms in the next two weeks following onset of COVID infection, with acute motor and sensory axonal neuropathy variant seen in almost one-fourth of cases [20]. Delayed response to anti-TB therapy (greater than eight weeks) in our case might suggest confounding etiology. It is still unclear whether COVID-19 had a direct impact or just a correlation.

\section{Conclusions}

Peripheral neuropathy could have a wide variety of causes and TB, the great mimicker of diseases should also be taken into consideration after exhausting the other common potential causes of neuropathy and for avoiding misdiagnosis. Moreover, there is still a considerable need for studies regarding the potential impact of COVID-19 on TB, regarding prognosis and severity of disease as well as the underlying mechanism by which TB affects extra-pulmonary structures, especially the peripheral nerves.

\section{Additional Information \\ Disclosures}

Human subjects: Consent was obtained by all participants in this study. Conflicts of interest: In compliance with the ICMJE uniform disclosure form, all authors declare the following: Payment/services info: Qatar National library which funded the open access publication fees of this case. Financial relationships: All authors have declared that they have no financial relationships at present or within the previous three years with any organizations that might have an interest in the submitted work. Other relationships: All authors have declared that there are no other relationships or activities that could appear to have influenced the submitted work.

\section{Acknowledgements}

We would like to thank Dr Mohammed Alhatou (Department of Neurology, Hamad Medical Corporation) for his valuable collaboration.

\section{References}

1. World Health Organization. Global tuberculosis report 2019. Geneva, Switzerland: World Health Organization. (2019). Accessed: October 21, 2020: https://www.who.int/teams/global-tuberculosisprogramme/tb-reports/global-report-2019.

2. Warpe BM, Poflee SV, Pande NP, Shrikhande AV: Tuberculous neuritis: a rare sequel of a common disease . Indian J Pathol Microbiol. 2014, 57:69-71. 10.4103/0377-4929.130902

3. Mafukidze AT, Calnan M, Furin J: Peripheral neuropathy in persons with tuberculosis . J Clin Tuberc Other Mycobact Dis. 2015, 2:5-11. 10.1016/j.jctube.2015.11.002

4. Sy KTL, Haw NJL, Jhanna Uy: Previous and active tuberculosis increases risk of death and prolongs recovery in patients with COVID-19. Infect Dis (Lond). 2020, 18:1-6. 10.1080/23744235.2020.1806353

5. Motta I, Centis R, D'Ambrosio L, et al.: Tuberculosis, COVID-19 and migrants: preliminary analysis of deaths occurring in 69 patients from two cohorts. Pulmonology. 2020, 26:233-240. 10.1016/j.pulmoe.2020.05.002

6. World Health Organization. Interactive timeline on COVID-19. (2020). Accessed: October 21, 2020: https://www.who.int/emergencies/diseases/novel-coronavirus-2019/interactive-timeline.

7. Liu C, Yu Y, Fleming J, et al.: Severe COVID-19 cases with a history of active or latent tuberculosis . Int J Tuberc Lung Dis. 2020, 24:747-749. 10.5588/ijtld.20.0163

8. Gupta N, Ish P, Gupta A, et al.: A profile of a retrospective cohort of 22 patients of COVID-19 with active/treated tuberculosis. Eur Respir J. 2020, 56:2003408. 10.1183/13993003.03408-2020

9. Kumar DR, Bhattacharya DB, Meena DV, Soneja DM, Wig DN: COVID-19 and TB co-infection - 'Finishing touch" in perfect recipe to 'severity' or 'death'. J Infect. 2020, 81:39-40. 10.1016/j.jinf.2020.06.062

10. Tham SM, Lim WY, Lee CK, et al.: Four patients with COVID-19 and tuberculosis, Singapore, April-May 2020. Emerg Infect Dis. 2020, 26: 10.3201/eid2611.202752 


\section{Cureus}

11. Yao Z, Chen J, Wang Q, et al.: Three patients with COVID-19 and pulmonary tuberculosis, Wuhan, China, January-February 2020. Emerg Infect Dis. 2020, 26: 10.3201/eid2611.201536

12. Stochino C, Villa S, Zucchi P, Parravicini P, Gori A, Raviglione MC: Clinical characteristics of COVID-19 and active tuberculosis co-infection in an Italian reference hospital. Eur Respir J. 2020, 56:2001708. 10.1183/13993003.01708-2020

13. Azhary H, Farooq MU, Bhanushali M, Majid A, Kassab MY: Peripheral neuropathy: differential diagnosis and management. Am Fam Phys. 2010, 81:887-892.

14. Jain AK, Kumar J: Tuberculosis of spine: neurological deficit. Eur Spine J. 2013, 22:624-633. 10.1007/s00586012-2335-7

15. Orrell RW, King RH, Bowler JV, Ginsberg L: Peripheral nerve granuloma in a patient with tuberculosis . I Neurol Neurosurg Psychiatry. 2002, 73:769-771. 10.1136/jnnp.73.6.769

16. Omar AT, Villaruel AR, Khu KJO: Tuberculoma of the peripheral nerve: illustrative case and systematic review of the literature. World Neurosurg. 2020, 137 :e547-e553. 10.1016/j.wneu.2020.02.031

17. Rafiei N, Khanlou N, Khosa S, Moheb N, Mishra SK: A case of tuberculosis-related leukocytoclastic vasculitis presenting with peripheral neuropathy. Cureus. 2018, 10:e3703. 10.7759/cureus.3703

18. Chen HA, Cheng NC, Lin KP, Liao HT, Chen CH, Huang DF: Mononeuropathy multiplex and chylothorax as earlier manifestations of pulmonary tuberculosis. J Intern Med. 2005, 257:561-563. 10.1111/j.13652796.2005.01495.x

19. Kalita I, Misra UK: Vitamin B12 deficiency neurological syndromes: correlation of clinical, MRI and cognitive evoked potential. J Neurol. 2008, 255:353-359. 10.1007/s00415-008-0660-X

20. De Sanctis P, Doneddu PE, Viganò L, Selmi, C, Nobile-Orazio E: Guillain Barré Syndrome associated with SARS-CoV-2 infection. A systematic review. Eur J Neurol. 2020, 27:2361-2370. 10.1111/ene.14462 